\title{
The Evaluation of Killer Cell Immunoglobulin-Like Receptor Gene Polymorphism in Glioblastoma Patients
}

\author{
Mustafa Emre SARAC ${ }^{1}$, Kadir OKTAY², Semih Kivanc OLGUNER ${ }^{3}$, Ozlem GORUROGLU OZTURK ${ }^{4}$, \\ Alp Iskender GOCER ${ }^{5}$ \\ ${ }^{1}$ Private South Adana Hospital, Department of Neurosurgery, Adana, Turkey \\ ${ }^{2}$ Gaziantep Medical Park Hospital, Department of Neurosurgery, Gaziantep, Turkey \\ ${ }^{3}$ Adana City Training and Research Hospital, Department of Neurosurgery, Adana, Turkey \\ ${ }^{4}$ Cukurova University School of Medicine, Department of Clinical Biochemistry, Adana, Turkey \\ ${ }^{5}$ Cukurova University School of Medicine, Department of Neurosurgery, Adana, Turkey \\ This study has been presented as an oral presentation at the $32^{\text {nd }}$ Annual Congress of Turkish Neurosurgical Society between 20 and 24 April 2018 at \\ Antalya, Turkey
}

Corresponding author: Kadir OKTAY drkadiroktay@hotmail.com

\section{ABSTRACT}

AIM: To assess the distribution of genetic polymorphisms of killer cell immunoglobulin-like receptors (KIRs) to predict the clinical course of glioblastoma, report on the genetic mechanisms, and provide guidance on potential therapeutic methods.

MATERIAL and METHODS: Our study included 31 adult patients who were admitted to the Department of Neurosurgery at our institution and diagnosed with glioblastoma between October 2013 and January 2014 together with 50 control subjects.

RESULTS: The mean age of the patients was 53.5 vs. 53.9 years, respectively, and the gender distribution (male/female: $64.5 / 35.5 \%$ vs. $64 / 36 \%$, respectively) was comparable among patients and controls ( $p>0.05$ ). Sixteen different KIR genes including inhibitory, activating, and pseudogenes were investigated for each sample, and the framework genes including KIR2DL4, 3DL2, 3DL3, and 3DP1 were present in all patients and controls. In addition, the inhibitory KIR genes and the 2DL3 gene were significantly more common in patients compared to controls $(p<0.05)$.

CONCLUSION: This study demonstrated that the inhibitory KIR gene 2DL3 has a predisposition for glioblastoma. Identifying the potential link between glioblastoma cells and immune system genetics is critical in predicting familial predisposition and early diagnosis. In addition, this clue may be a key factor in developing post-surgery individual immunotherapy models in the future.

KEYWORDS: Glioblastoma, Killer cell immunoglobulin-like receptor gene, Natural killer cells, Spesific oligonucleotid probes method

\section{INTRODUCTION}

$\mathrm{G}$ lioblastoma is the most common and the most deadly primary brain tumor (29). The primary course of treatment includes maximal surgical resection, followed by radiotherapy with concurrent temozolomide therapy (29). In recurring tumors, salvage therapy options include repeat surgical resection, antiangiogenic therapy (bevacizumab), and various investigational therapies including immunotherapy and other chemotherapeutic agents $(7,21)$. Despite aggressive treatment, the median survival time is only $18-24$ months. The limited treatment success is partially due to intrinsically aggressive tumor behavior but also to the heterogeneity of the disease $(2,15)$.

The most important cells of the immune system are natural killer cells (NK), which are large granular lymphocytes originating from the bone marrow. The cytotoxic response
Mustafa Emre SARAC Kadir OKTAY

(D) : $0000-0003-2420-3428$

(iD : $0000-0003-2420-2734$

Semih Kivanc OLGUNER (D) : 0000-0006-2830-3442
Ozlem GORUROGLU OZTURK (D) : 0000-0002-8657-2964

Alp Iskender GOCER
: 0000-0002-4148-3852 
of NK cells is controlled by the balance between signals from the activating or inhibitory receptors on the surface. One such group of receptors is the NK cell immunoglobulinlike receptors (KIR). KIR receptors distinguish the cells in an organism by their human leukocyte antigen (HLA) class I molecules, while foreign cells are distinguished by the absence of these molecules (31). Since the characterization of KIR genes is very recent, few studies have reported on their relationship to specific diseases $(8,25,28,31)$.

Positive results from genetic studies are leading to the development of possible gene therapies for diseases with high mortality and morbidity and no definitive treatment. Based on our current knowledge, no studies have reported on the polymorphism of KIR genes in glioblastoma. In this study, we aimed to compare the KIR gene polymorphism in cases of glioblastoma with healthy controls to predict the possible genetic predisposition and clinical course of the disease. It is also possible that the obtained results could be used in the future in individual gene therapy for this disease.

\section{MATERIAL and METHODS}

Our research was performed according to the principles of the Declaration of Helsinki, and the Institutional Ethical Review Board approval was obtained (6 December 2013, no: 17). In total, we included 31 adult patients who were diagnosed and treated for glioblastoma in the department of neurosurgery at our institution between October 2013 and January 2014. The control group comprised 50 individuals without any nervous system trauma, vascular or inflammatory diseases, or neoplasia. After obtaining informed consent from each patient or the patient's relatives, we gathered patient data including age, sex, place of birth, chronic viral diseases, autoimmune diseases (familial mediterranean fever [FMF], rheumatoid arthritis, ankylosing spondylitis, systemic lupus erythematosus [SLE]), cancer history, family history, and pregnancy. After isolating the DNA, we performed KIR genotyping using the sequence-specific oligonucleotide probes method.

\section{KIR Genotyping}

We extracted DNA from venous blood samples of each subject using a DNA isolation kit (QIAamp DNA Blood Mini Kit, Cat No. 51104; QIAGEN Vertriebs GmbH, Vienna, Austria). Genotyping of the KIR genes was performed using the multiplex KIR-SSO typing kit (Tepnel Lifecodes Corp., Ref: 545110; Connecticut, USA), which consists of a mixture of locus-specific oligonucleotide probes coupled to color-coded microspheres (Luminex Corp.) and two polymerase chain reaction (PCR) tests to amplify KIR exons 4, 5, 7, 8, and 9. PCR was performed on each sample, and the product was hybridized with the SSO-probe mixture according to the manufacturer's instructions. After hybridization, the sample plate was placed in a Luminex instrument for analysis (24).

\section{Prediction of Group A/B KIR Haplotype}

The frequencies of groups $A$ and $B$ KIR haplotypes were deduced from the genotyping data $(9,12)$. Individuals carrying only KIR3DL3, 2DL3, 2DL1, 2DP1, 3DP1, 2DL4, 3DL1, 2DS4 and $3 D L 2$, a fixed gene content characteristic of group $A$ haplotypes, were considered to carry two copies of group A KIR haplotypes (AA genotypes), whereas the those carrying KIR2DL2, 2DL5, 3DS1, 2DS1, 2DS2, 2DS3, and/or 2DS5 were considered to carry a $\mathrm{B}$ haplotype $(\mathrm{Bx})$.

\section{Statistical Analyses}

The percentage of each KIR gene in the two groups was calculated by direct counting (individuals positive for the gene/individuals tested per population $\times 100$ ). Data analysis was performed using the statistical software Minitab, version 17. Differences in the distribution of each KIR gene between the two groups were estimated using a two-tailed Fisher's exact test, and $\mathrm{p}<0.05$ was considered statistically significant.

\section{- RESULTS}

In the present study, we evaluated a total of 81 subjects, including 31 with glioblastoma who were referred to neurosurgical wards and outpatient services together with 50 individuals in the control group. Overall, 20 males (64.5\%) and 11 females (35.5\%) comprised the patient group. Of controls, 32 were male (64\%) and 18 were female (36\%). Glioblastoma patients had a mean age of 53.5 years compared to a mean age of 53.9 years in the control group.

Figure 1 shows the genotype distribution in our 31 glioblastoma patients. In the study, a total of 16 different KIR genes, inhibitory, activating, and pseudogene, were studied, and the framework genes, including KIR2DL4, 3DL2, 3DL3, and 3DP1, were present in all patients in both groups (Table I). The 2DL3 gene, one of the inhibitory genes, was more common in patients than controls, and the difference was statistically significant $(p<0.05)$ (Figure 2).

\section{DISCUSSION}

Glioblastomas are classified as glioblastoma, IDH-wild-type; glioblastoma, IDH-mutant; and glioblastoma, NOS according to the 2016 World Health Organization Classification of Tumors of the Central Nervous System. Glioblastoma, IDH-wild-type constitutes approximately $90 \%$ of cases and corresponds most frequently with clinically defined primary or de novo glioblastoma. It is mainly found in patients aged $>55$ years. Glioblastoma, IDH-mutant, which usually affects younger patients, comprises only $10 \%$ of cases and corresponds to secondary glioblastoma with a history of prior lower-grade diffuse glioma. Glioblastoma, NOS is a diagnosis reserved for those tumors in which full IDH evaluation cannot be performed $(16,23)$. Epithelioid glioblastoma is a new variant of glioblastoma that joins giant cell glioblastoma and gliosarcoma under the umbrella of IDH-wild type glioblastoma (7). This tumor is usually identified in children and younger adults, typically presents as superficial cerebral or diencephalic masses, and often harbors a BRAF V600E mutation (which can be detected immunohistochemically) $(5,10,11)$.

Glioblastoma with primitive neuronal component was added to the 2016 WHO Classification as a pattern in glioblastoma. This pattern, previously known in the literature as glioblastoma with PNET-like component, usually consists of a diffuse 
astrocytoma of any grade (or oligodendroglioma in rare cases) with well-demarcated nodules containing primitive cells that display neuronal differentiation (e.g., Homer-Wright rosettes, gain of synaptophysin positivity, and loss of GFAP expression) and that sometimes have MYC or MYCN amplification; these tumors have a tendency for craniospinal fluid dissemination (26).

Table I: Frequency of Inhibitor and Activator Genes

\begin{tabular}{|c|c|c|c|c|c|c|}
\hline & Gene & \multicolumn{2}{|c|}{ Patient Group } & \multicolumn{2}{|c|}{ Control Group } & $\mathbf{p}$ \\
\hline \multirow{7}{*}{ Inhibitor KIR } & 2DL1 & 31 & 100.0 & 48 & 94.1 & 0.522 \\
\hline & 2DL2 & 13 & 41.9 & 29 & 56.9 & 0.177 \\
\hline & 2DL3* & 24 & 77.4 & 13 & 25.5 & 0.002 \\
\hline & 2DL5 & 16 & 51.6 & 32 & 62.7 & 0.353 \\
\hline & 3DL1 & 23 & 74.2 & 43 & 84.3 & 0.242 \\
\hline & 3DL2 & 31 & 100.0 & 50 & 98.0 & 1.0 \\
\hline & 3DL3 & 31 & 100.0 & 50 & 98.0 & 1.0 \\
\hline \multirow{4}{*}{ Activator KIR } & 2DS3 & 9 & 29.0 & 21 & 41.2 & 0.344 \\
\hline & 2DS4 & 31 & 100.0 & 50 & 98.0 & 1.0 \\
\hline & 2DS5 & 12 & 38.7 & 21 & 41.2 & 0.819 \\
\hline & 3DS1 & 12 & 38.7 & 10 & 19.6 & 0.077 \\
\hline \multirow{2}{*}{ Pseudogene } & 2DP1 & 31 & 100.0 & 48 & 94.1 & 0.522 \\
\hline & 3DP1 & 31 & 100.0 & 50 & 98.0 & 1.0 \\
\hline
\end{tabular}

${ }^{*}$ The relation of $2 D L 3$ gene to Susceptibility to disease is statistically significant $(p<0.05)$.

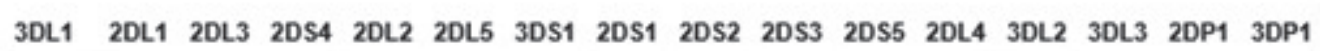

Total Genotype patient

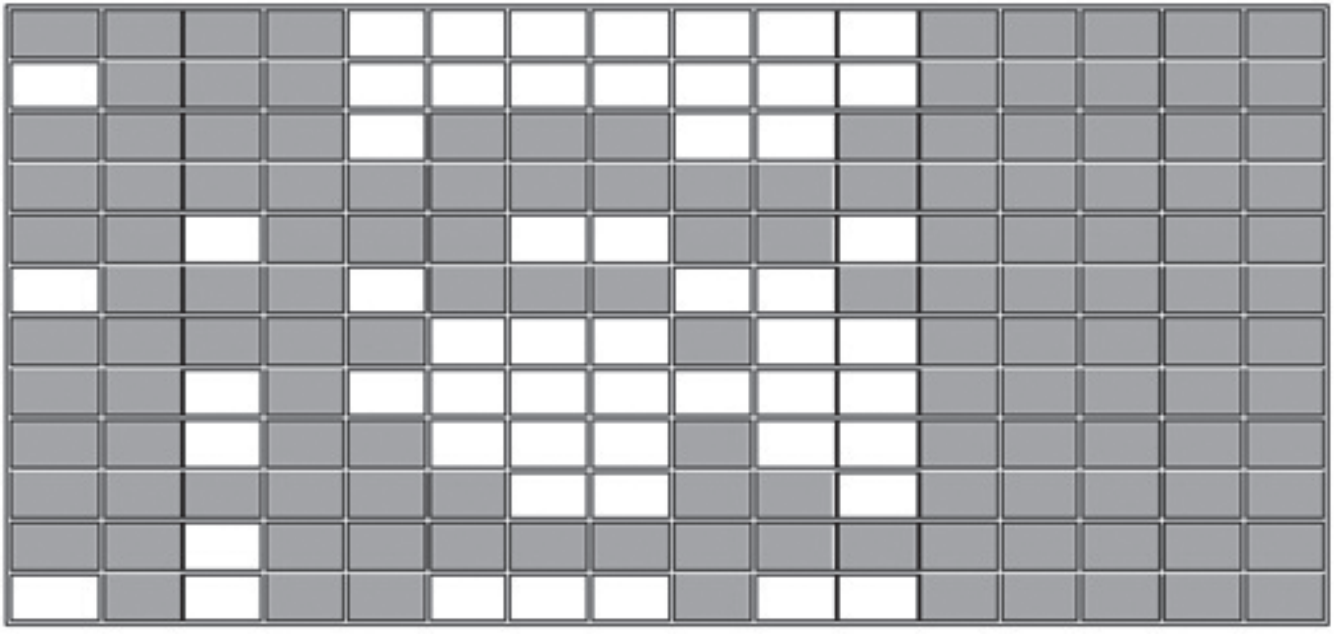

$\begin{array}{cc}6 & \text { AA1 } \\ 4 & \text { AA156 } \\ 4 & B \times 2 \\ 4 & B \times 6 \\ 3 & B \times 71 \\ 3 & B \times 154 \\ 2 & B \times 4 \\ 1 & A A 180 \\ 1 & B \times 317 \\ 1 & B \times 5 \\ 1 & B \times 73 \\ 1 & B \times 187\end{array}$

Figure 1: Genotype distributions of patients. 


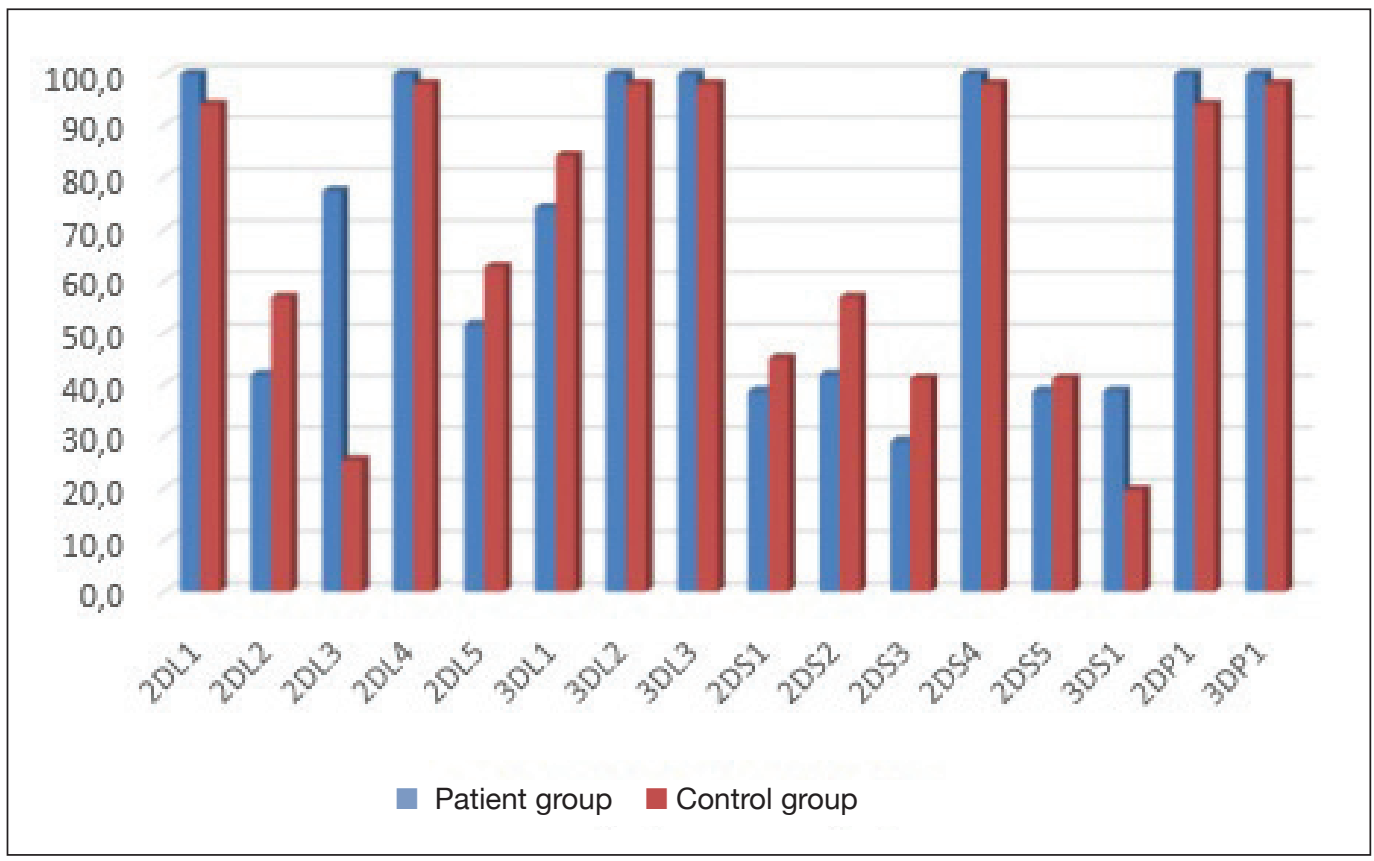

Figure 2: The frequency of inhibitor and activator genes in the patient and control groups.
KIRs are a family of inhibitory and activating receptors produced by NK cells that regulate the activation of NK cells, and they are polymorphic markers. KIR genes are widely believed to co-develop with HLA ligands (28). In addition, genotypic KIR diversity is a result of allelic and haplotypic diversity. Thus, it is extremely difficult to detect the same KIR genotype in two unrelated individuals (25). Due to these characteristics, KIR genes are considered good markers of determining population genetics $(8,20)$.

Independent studies on the KIR genes were combined and added to the knowledge database prepared for HLA in 2003. T-cell-mediated suppression of class I HLA surface molecules used by tumor cells as an escape mechanism makes NK cells more susceptible to cell-mediated lysis. In this case, individual changes in the KIR genes of NK cells only explain the ability of some NK cells to destroy tumors. NK cells may interfere with viral-infected or malignant transformed cells via KIR with lysis and cell-mediated cytotoxicity and antibody-mediated cellular cytotoxicity $(8,20,25,28)$.

Studies have reported that specific KIR genes and KIR ligands may beassociated with prophylaxis or susceptibility toleukemia and solid tumors $(1,3,4,6,14,18,19,22,24,32)$. However, the role KIR gene polymorphism plays in the development of glioblastoma is not known. The purpose of our study was to analyze the possible roles of KIR gene polymorphisms in glioblastoma patients. We investigated a total of 81 subjects, with 31 having glioblastoma patients and 50 serving as the control group, in order to evaluate the relationship between KIR polymorphism and glioblastoma. KIR framework genes 2DL4, 3DL2, 3DL3, and 3DP1 were present in all individuals in both groups. 2DL3, an inhibitory KIR gene, was more common in the patient group $(p<0.05)$. These results demonstrated a statistically significant relationship between the 2DL3 gene and glioblastoma development.
The 2012 study by Ozturk et al. showed that the framework genes KIR2DL4, 3DL2, 3DL3, and 3DP1 were seen in all patients and controls (24). The rate of activating KIR2DS1 was much higher in patients with breast cancer than in healthy controls, while the allelic types of activating 2DS4 (2DS4*003/4/6/7) were lower in patients with breast cancer than in healthy controls. In addition, a statistically significant negative correlation was seen between 2DL1 genes and breast cancer development. They concluded that activating KIR2DS1 may trigger breast cancer development, while 2DL1 gene and $2 \mathrm{DS} 4^{*} 003 / 4 / 6 / 7$ alleles may possibly protect against breast cancer (24).

Middleton et al. analyzed the frequency of KIR in cohorts of Turkish patients with acute lymphocytic leukemia, acute myeloid leukemia, and chronic myeloid leukemia and compared the results with those of 154 controls (18). They proposed a model of protection against chronic myeloid leukemia via KIR2DL2 and/or KIR2DS2 with the presence of the ligand HLA-C1 group and susceptibility via HLA-Bw4 homozygosity. Besson et al. indicated that KIR3DS1 and KIR2DS1 activating genes were associated with protection against Hodgkin lymphoma (4).

A study by Lopez-Vazquez et al. examined the HLA and KIR genotypes, showing that the interaction between KIR3DS1 and HLA-Bw4 allotypes was protective against the development of hepatocellular carcinoma (14). Abnormal KIR expression has been associated with numerous malignant conditions. An increasing number of activating KIR genes has been associated with nasopharyngeal carcinoma (6). KIR3DL2 is shown to synthesize in phenotypically abnormal $\mathrm{T}$ cells in patients with Sézary syndrome (3). Inhibitory KIR is synthesized in subtypes of T-cell large granular lymphocytic leukemia, and the absence of HLA ligands for synthesized KIRs increases disease severity $(19,22)$. 
Al Omar et al. found no statistically significant difference in terms of KIR genes when comparing healthy individuals with those patients who had solid tumors (non-small-cell lung cancer, small-cell lung cancer, colon cancer, kidney cancer) (1). Zhang et al. reported that the activating KIR2DS4 gene was associated with the development of chronic myeloid leukemia (32). Meanwhile, 2DS3, another activating gene, had a lower frequency in patients with acute lymphoblastic leukemia compared to healthy individuals.

In the present study, we demonstrated that patients with glioblastoma had increased levels of KIR2DL3. In the literature, this gene is associated with clinical conditions including HIV infection, trachoma, SLE, and hepatitis C virus infection $(13,17,27,30)$. Ma et al. evaluated 24 patients diagnosed with SLE and found that the number of KIR2DL3 (+) NK cells was negatively correlated with SLE Disease Activity Index Scores at 4 weeks post-treatment (17). In another study, increased KIR2DL3 inhibitory receptor expression by NK and cytotoxic $T$ cells in patients with chronic hepatitis $C$ were associated with cellular immune defects (30). Roberts et al. indicated that high levels of KIR2DL2 and KIR2DL3 increased the risk of conjunctival scarring in patients with trachoma (27). However, we could not find any study reporting a relationship between the KIR2DL3 gene and brain tumors. According to our review of the literature, this is the first article to report an association between KIR2DL3 gene and brain tumors.

Our study has certain limitations. The study was performed between October 2013 and January 2014; therefore, due to the timing of the study, the patients' pathological assessments were not performed according to the new classification, and this is the main limitation of the study. In addition, the patient group was small. There are also no data regarding the impact of this finding on patient survival or prognosis. Further studies including large groups of patients and long follow-up would aid in making more definite conclusions.

We think that such complex information regarding the role of KIR genes in tumor development is due to the existence of many different potential pathological mechanisms, immunological responses, and immunological escape mechanisms in differentiated cancers. These data suggest that the increase in activating KIR genotypes may have protective effects against various types of cancer, while the increase in inhibitory KIR may provide a basis for cancer development.

\section{CONCLUSION}

The results of the present study suggest that high levels of KIR2DL3, an inhibitory receptor of NK cells, in a glioblastoma patient population negatively impact the protective role of these cells in the immune system and, as a result, the necessary immune response was not achieved. These data provide stronger evidence that the immune system has the ability to recognize and exterminate glioblastoma cells. They also suggest that glioblastoma cells are able to escape from the immune system. Understanding the genetic structure of tumors encourages the development of new, individualspecific treatments for tumors such as glioblastoma that do not have a definitive treatment modality. The relationship of glioblastoma cells to immunosystemic genetics is important in predicting familial predispositions, early diagnosis, and the development of personalized therapy after surgery.

\section{ACKNOWLEDGEMENTS}

Preparation for publication of this article is partly supported by Turkish Neurosurgical Society.

\section{REFERENCES}

1. Al Omar S, Middleton D, Marshall E, Porter D, Xinarianos G, Raji O, Field JK, Christmas SE: Associations between genes for killer immunoglobulin-like receptors and their ligands in patients with solid tumors. Hum Immunol 71(10):976-981, 2010

2. Auffinger B, Thaci B, Nigam $P$, Rincon E, Cheng $Y$, Lesniak MS: New therapeutic approaches for malignant glioma: In search of the Rosetta stone. F1000 Med Rep 4:18, 2012

3. Bahler DW, Hartung L, Hill S, Bowen GM, Vonderheid EC: CD158k/KIR3DL2 is a useful marker for identifying neoplastic T-cells in Sezary syndrome by flow cytometry. Cytometry B Clin Cytom 74(3):156-162, 2008

4. Besson C, Roetynck S, Williams F, Orsi L, Amiel C, Lependeven C, Antoni G, Hermine O, Brice P, Ferme C, Carde P, Canioni $\mathrm{D}$, Brière $\mathrm{J}$, Raphael $\mathrm{M}$, Nicolas JC, Clavel J, Middleton D, Vivier E, Abel L: Association of killer cell immunoglobulin-like receptor genes with Hodgkin's lymphoma in a familial study. PLoS One 2(5):e406, 2007

5. Broniscer A, Tatevossian RG, Sabin ND, Klimo P Jr, Dalton J, Lee R, Gajjar A, Ellison DW: Clinical, radiological, histological and molecular characteristics of paediatric epithelioid glioblastoma. Neuropathol Appl Neurobiol 40(3):327-336, 2014

6. Butsch Kovacic M, Martin M, Gao X, Fuksenko T, Chen CJ, Cheng YJ, Chen JY, Apple R, Hildesheim A, Carrington M: Variation of the killer cell immunoglobulin-like receptors and HLA-C genes in nasopharyngeal carcinoma. Cancer Epidemiol Biomarkers Prev 14(11 Pt 1):2673-2677, 2005

7. Chow D, Chang P, Weinberg BD, Bota DA, Grinband J, Filippi CG: Imaging genetic heterogeneity in glioblastoma and other glial tumors: Review of current methods and future directions. AJR Am J Roentgenol 210(1):30-38, 2018

8. Denis L, Sivula J, Gourraud PA, Kerdudou N, Chout R, Ricard C, Moisan JP, Gagne K, Partanen J, Bignon JD: Genetic diversity of KIR natural killer cell markers in populations from France, Guadeloupe, Finland, Senegal and Reunion. Tissue Antigens 66(4):267-276, 2005

9. Gonzalez-Galarza FF, Takeshita LY, Santos EJ, Kempson F, Maia MH, da Silva AL, Teles e Silva AL, Ghattaoraya GS, Alfirevic A, Jones AR, Middleton D: Allele frequency net 2015 update: New features for HLA epitopesi KIR and disease and HLA adverse drug reaction associations. Nucleic Acids Res 43:D784-788, 2015

10. Kleinschmidt-DeMasters BK, Aisner DL, Birks DK, Foreman NK: Epithelioid GBMs show a high percentage of BRAF V600E mutation. Am J Surg Pathol 37(5):685-698, 2013 
11. Kleinschmidt-DeMasters BK, Alassiri AH, Birks DK, Newell $\mathrm{KL}$, Moore W, Lillehei KO: Epithelioid versus rhabdoid glioblastomas are distinguished by monosomy 22 and immunohistochemical expression of INI-1 but not claudin 6 . Am J Surg Pathol 34(3):341-354, 2010

12. Levinson RD, Du Z, Luo L, Holland GN, Rao NA, Reed EF, Rajalingam R: KIR and HLA gene combinations in VogtKoyanagi-Harada disease. Hum Immunol 69(6):349-353, 2008

13. Lisovsky I, Isitman G, Tremblay-Mclean A, Song R, DaFonseca S, Lebouche B, Routy JP, Bruneau J, Bernard NF: The differential impact of natural killer (NK) cell education via KIR2DL3 and KIR3DL1 on CCL4 secretion in the context of in-vitro HIV infection. Clin Exp Immunol 186(3):336-346, 2016

14. Lopez-Vazquez A, Rodrigo L, Martinez-Borra J, Pérez R, Rodríguez M, Fdez-Morera JL, Fuentes D, Rodríguez-Rodero S, Gonzáez S, López-Larrea C: Protective effect of the HLA-Bw4I80 epitope and the killer cell immunoglobulin-like receptor 3DS1 gene against the development of hepatocellular carcinoma in patients with hepatitis $\mathrm{C}$ virus infection. $\mathrm{J}$ Infect Dis 192(1):162-165, 2005

15. Louis DN, Perry A, Burger P, Ellison DW, Reifenberger G, von Deimling A, Aldape K, Brat D, Collins VP, Eberhart C, FigarellaBranger D, Fuller GN, Giangaspero F, Giannini C, Hawkins C, Kleihues P, Korshunov A, Kros JM, Beatriz Lopes M, Ng HK, Ohgaki H, Paulus W, Pietsch T, Rosenblum M, Rushing E, Soylemezoglu F, Wiestler O, Wesseling P; International Society of Neuropathology Haarlem: International Society of Neuropathology-Haarlem consensus guidelines for nervous system tumor classification and grading. Brain Pathol 24(6):429-435, 2014

16. Louis DN, Perry A, Reifenberger G, von Deimling A, FigarellaBranger D, Cavenee WK, Ohgaki H, Wiestler OD, Kleihues P, Ellison DW: The 2016 World Health Organization Classification of Tumors of the Central Nervous System: A summary. Acta Neuropathol 131(6):803-820, 2016

17. Ma H, Zhao L, Jiang Z, Jiang Y, Feng L, Ye Z: Dynamic changes in the numbers of different subsets of peripheral blood NK cells in patients with systemic lupus erythematosus following classic therapy. Clin Rheumatol 33(11):1603-1610, 2014

18. Middleton D, Diler AS, Meenagh A, Sleator C, Gourraud PA: Killer immunoglobulin-like receptors (KIR2DL2 and/or KIR2DS2) in presence of their ligand (HLA-C1 group) protect against chronic myeloid leukaemia. Tissue Antigens 73(6):553560, 2009

19. Morice WG, Kurtin PJ, Leibson PJ, Tefferi A, Hanson CA: Demonstration of aberrant T-cell and natural killer-cell antigen expression in all cases of granular lymphocytic leukaemia. $\mathrm{Br}$ J Haematol 120(6):1026-1036, 2003

20. Niokou D, Spyropoulou-Vlachou M, Darlamitsou A, Stavropoulos-Giokas C: Distribution of killer cell immunoglobulin-like receptors in the Greek population. Hum Immunol 64(12):1167-1176, 2003
21. Nonoguchi N, Ohta T, Oh JE, Kim YH, Kleihues P, Ohgaki $\mathrm{H}$ : TERT promoter mutations in primary and secondary glioblastomas. Acta Neuropathol 126(6):931-937, 2013

22. Nowakowski GS, Morice WG, Phyliky RL, Li CY, Tefferi A: Human leucocyte antigen class I and killer immunoglobulinlike receptor expression patterns in T-cell large granular lymphocyte leukaemia. Br J Haematol 128(4):490-492, 2005

23. Ohgaki $\mathrm{H}$, Kleihues $\mathrm{P}$ : The definition of primary and secondary glioblastoma. Clin Cancer Res 19(4):764-772, 2013

24. Ozturk OG, Gun FD, Polat G: Killer cell immunoglobulin-like receptor genes in patients with breast cancer. Med Oncol 29(2):511-515, 2012

25. Pavlova Y, Kolesar L, Striz I, Jabor A, Slavcev A: Distribution of KIR genes in the Czech population. Int $\mathrm{J}$ Immunogenet 35(1):57-61, 2008

26. Perry A, Miller CR, Gujrati M, Scheithauer BW, Zambrano SC, Jost SC, Raghavan R, Qian J, Cochran EJ, Huse JT, Holland EC, Burger PC, Rosenblum MK: Malignant gliomas with primitive neuroectodermal tumor-like components: A clinicopathologic and genetic study of 53 cases. Brain Pathol 19(1):81-90, 2009

27. Roberts $\mathrm{CH}$, Molina S, Makalo P, Joof H, Harding-Esch EM, Burr SE, Mabey DC, Bailey RL, Burton MJ, Holland MJ: Conjunctival scarring in trachoma is associated with the HLA-C ligand of KIR and is exacerbated by heterozygosity at KIR2DL2/KIR2DL3. PLoS Negl Trop Dis 8(3):e2744, 2014

28. Sanchez-Mazas A, Fernandez-Vina M, Middleton D, Hollenbach JA, Buhler S, Di D, Rajalingam R, Dugoujon JM, Mack SJ, Thorsby E: Immunogenetics as a tool in anthropological studies. Immunology 133(2):143-164, 2011

29. Stupp R, Mason WP, van den Bent MJ, Weller M, Fisher B, Taphoorn MJ, Belanger K, Brandes AA, Marosi C, Bogdahn U, Curschmann J, Janzer RC, Ludwin SK, Gorlia T, Allgeier A, Lacombe D, Cairncross JG, Eisenhauer E, Mirimanoff RO; European Organisation for Research and Treatment of Cancer Brain Tumor and Radiotherapy Groups; National Cancer Institute of Canada Clinical Trials Group: Radiotherapy plus concomitant and adjuvant temozolomide for glioblastoma. $\mathrm{N}$ Engl J Med 352(10):987-996, 2005

30. Szereday L, Meggyes M, Halasz M, Szekeres-Bartho J, Par A, Par G: Immunological changes in different patient populations with chronic hepatitis $\mathrm{C}$ virus infection. World J Gastroenterol 22(20):4848-4859, 2016

31. Warren HS, Campbell AJ, Waldron JC, Lanier LL: Biphasic response of $\mathrm{NK}$ cells expressing both activating and inhibitory killer Ig-like receptors. Int Immunol 13(8):1043-1052, 2001

32. Zhang Y, Wang B, Ye S, Liu S, Liu M, Shen C, Teng Y, Qi J: Killer cell immunoglobulin-like receptor gene polymorphisms in patients with leukemia: Possible association with susceptibility to the disease. Leuk Res 34(1):55-58, 2010 